\title{
Diagnostic accuracy of diffusion weighted imaging for differentiation of supratentorial pilocytic astrocytoma and pleomorphic xanthoastrocytoma
}

\author{
Dejun She ${ }^{1} \cdot$ Jianyi Liu ${ }^{1} \cdot$ Z. Zeng ${ }^{2} \cdot$ Z. Xing $^{1} \cdot$ Dairong Cao $^{1}$ (D) \\ Received: 18 January 2018 / Accepted: 14 May 2018 / Published online: 24 May 2018 \\ (C) The Author(s) 2018
}

\begin{abstract}
Purpose Supratentorial pilocytic astrocytoma (PA) may mimic pleomorphic xanthoastrocytoma (PXA) on conventional MR imaging, and a differentiation is clinically important because of distinct recurrence rate and anaplastic transformation rate. The purpose of this study was to investigate the diagnostic potential of diffusion-weighted imaging (DWI) in differentiating supratentorial PA from PXA.

Methods We retrospectively reviewed DWI and conventional MR imaging of 16 patients with supratentorial PA and 8 patients with PXA. Variables of mean $\mathrm{ADC}$ values $\left(\mathrm{ADC}_{\text {mean }}\right)$ and minimum $\mathrm{ADC}$ values $\left(\mathrm{ADC}_{\mathrm{min}}\right)$ were calculated from the ROIs containing the contrast-enhancing lesion on DWI. $\mathrm{ADC}_{\text {mean }}$ values and $\mathrm{ADC}_{\mathrm{min}}$ values were compared among all supratentorial PA and PXA as well as between the subgroup of lobar PA and PXA by using an unpaired Student's $t$ test. The optimum threshold, sensitivity, specificity, accuracy, and the area under the receiver operating characteristic curve (AUC) were determined.

Results Both $\mathrm{ADC}_{\text {mean }}$ values $\left(1542 \pm 186 \mathrm{vs} 1084 \pm 201 \times 10^{-6} \mathrm{~mm}^{2} / \mathrm{s} ; P<0.001\right)$ and $\mathrm{ADC}_{\min }$ values $(1355 \pm 183 \mathrm{vs} 988 \pm$ $180 \times 10^{-6} \mathrm{~mm}^{2} / \mathrm{s} ; P<0.001$ ) were significantly higher in supratentorial PA compared with $\mathrm{PXA}$. The $\mathrm{ADC}_{\text {mean }}$ values and $\mathrm{ADC}_{\min }$ values were also significantly higher in lobar PA than those in PXA. The $\mathrm{ADC}_{\text {mean }}$ values were useful for differentiating supratentorial PA from PXA, with a threshold value of $>1189.8 \times 10^{-6} \mathrm{~mm}^{2} / \mathrm{s}$ (sensitivity, $93.8 \%$; specificity, $100 \%$ ). The optimal threshold values of $>1189.8 \times 10^{-6} \mathrm{~mm}^{2} / \mathrm{s}$ for $\mathrm{ADC}_{\text {mean }}$ values provide sensitivity and specificity of 85.7 and $100 \%$, respectively, for discriminating lobar PA from PXA. The optimum threshold value for $\mathrm{ADC}_{\min }$ was $>1063.5 \times 10^{-6} \mathrm{~mm}^{2} / \mathrm{s}$.

Conclusion DWI is helpful in characterization and differentiation of supratentorial PA from PXA.
\end{abstract}

Keywords Supratentorial pilocytic astrocytoma $\cdot$ Pleomorphic xanthoastrocytoma $\cdot$ Diffusion-weighted imaging

Abbreviations
PA Pilocytic astrocytoma
WHO World Health Organization
PXA Pleomorphic xanthoastrocytoma
Electronic supplementary material The online version of this article
(https://doi.org/10.1007/s00234-018-2036-y) contains supplementary
material, which is available to authorized users.

Dairong Cao

dairongcao@163.com

1 Department of Radiology, First Affiliated Hospital of Fujian Medical University, 20 Cha-Zhong Road, 350005 Fuzhou, Fujian, People's Republic of China

2 Department of Medical Imaging Technology, College of Medical Technology and Engineering, Fujian Medical University, 350108 Fuzhou, Fujian, People's Republic of China

$\begin{array}{ll}\text { DWI } & \text { Diffusion-weighted imaging } \\ \text { ADC } & \text { Apparent diffusion coefficient } \\ \text { TR } & \text { Repetition time } \\ \text { TE } & \text { Echo time } \\ \text { FOV } & \text { Field of view } \\ \text { ROI } & \text { Region of interest } \\ \text { ADC }_{\text {mean }} & \text { Mean ADC values } \\ \text { ADC }_{\text {min }} & \text { Minimum ADC values } \\ \text { ROC } & \text { Receiver operating characteristic } \\ \text { AUC } & \text { Area under curve } \\ \text { ICC } & \text { Intraclass correlation test }\end{array}$

\section{Introduction}

Pilocytic astrocytoma (PA) is classified as World Health Organization (WHO) grade I tumor, which occurs most 
commonly in children and young adults [1]. This tumor usually arises from the cerebellum, but it can also occur in the supratentorial compartment including the optic nerve and chiasm, cerebral hemispheres, hypothalamus, or cerebral ventricles [2]. Pleomorphic xanthoastrocytoma (PXA) is a rare brain tumor and is classified as grade II according to the 2016 WHO classification system [3]. PXA typically occurs in the supratentorial brain, most frequently affecting children and adolescent [4]. Both PA and PXA are potentially curable by total surgical resection and are associated with a longer overall survival $[5,6]$, but the patients with PXA have a far worse prognosis than those with PA, especially in younger patients [4]. Although PXA is considered a benign tumor, populationbased studies suggested that this tumor was associated with higher risk of recurrence and anaplastic transformation compared with PA [1, 5, 7-10]. Thus, the differentiation of PXA from PA is important clinically.

PA could be reliably differentiated from PXA when PA occurs in the cerebellum on conventional MR. Unfortunately, when PA occurs in the supratentorial brain, differential diagnosis of supratentorial PA and PXA can be challenging on conventional MR imaging due to their similar neuroradiological presentations, typically appearing as a large cystic mass with a mural-enhancing nodule [6]. Given that differentiation of supratentorial PA and PXA is challenging to the neuroradiologist, diffusion-weighted imaging (DWI) might complement functional and physiological information in addition to that obtained with the anatomic MRI [11-14]. DWI could noninvasively evaluate the Brownian movement of water molecules and reflect tissue cellularity by apparent diffusion coefficient (ADC) values, which may be helpful in the preoperative diagnosis and grading of brain astrocytoma [11-13, 15]. Although both PA and PXA belong to the same family of low-grade astrocytoma, PA may present with histologic structures different from those found in PXA. Therefore, the application of DWI technique may better evaluate and distinguish the cytostructural differences occurring between $\mathrm{PA}$ and PXA.

To date, DWI studies in low-grade glioma and on glioma grading have not reported ADC values of PA separately from PXA [15-17]. The aim of this study was to investigate the diagnostic potential of DWI in differentiating supratentorial PA from PXA.

\section{Materials and methods}

\section{Patients}

This retrospective study was approved by the institutional review board of our hospital, and written informed consent was waived due to its retrospective nature. From March 2010 through October 2017, potentially eligible patients with pathologically confirmed supratentorial PA and PXA were identified. For the selection of appropriate patients, those with obvious hemorrhagic lesions, previously treated, or incomplete DWI raw data were excluded. The patients with pathologically confirmed anaplastic PXA were also excluded. Pretreatment MR images of consecutive patients were reviewed retrospectively, and DWI was requested in addition to conventional MRI.

All patients underwent surgical resection after MR examination. Tumor specimens were fixed in $10 \%$ phosphatebuffered formalin, embedded in paraffin, and representative slides were stained with hematoxylin-eosin reagent for standard histological diagnosis based on the histologic features by a neuropathologist ( 8 years of experience in histology) according to the 2016 WHO classification of tumors of the central nervous system (revised 4th edition) [18].

\section{Imaging protocols}

Imaging was performed with a $3.0 \mathrm{~T}$ MR system (Skyra; Siemens, Erlangen, Germany) or another 3.0 T MR system (Magnetom Verio; Siemens, Erlangen, Germany) using a head coil. The conventional MR imaging sequences were performed by using axial T2WI, axial and sagittal T1WI, axial FLAIR, and contrast-enhanced T1WI in 3 orthogonal planes. FOV at $220 \mathrm{~mm}$, section thickness of $5 \mathrm{~mm}$, and intersection gap of $1 \mathrm{~mm}$ were uniform in all sequences.

Echo-planar DWI was acquired in the transversal plane with $b=0$ and $1000 \mathrm{~s} / \mathrm{mm}^{2}$. Acquisition parameters for the DWI sequence were as follows: repetition time (TR)/echo time (TE), 8200/102 ms; FOV, $220 \mathrm{~mm}$; section thickness, $5 \mathrm{~mm}$; intersection gap, $1 \mathrm{~mm}$; NEX, 2.0. DWI was performed before administration of contrast material. Processing of the ADC map was generated automatically on the MR unit.

\section{Data processing}

An experienced neuroradiologist (D.C., with 25 years of brain MR imaging experience) who was blinded to histopathologic results retrospectively interpreted all MR images. The reader evaluated each lesion and recorded the following MR findings: (a) tumor location, (b) predominant radiologic pattern (a cystic mass with a mural nodule or a predominantly solid mass), (c) peritumoral edema, (d) contrast enhancement pattern (mild enhancement or marked enhancement), (e) presence of adjacent leptomeningeal involvement (dural tail sign), and (f) presence of inner tables scalloping. The tumor location was defined as the main lobe when more than one lobe was involved by the lesion. For evaluation of DWI sequence, qualitative assessment of the DWI signal intensity in the contrastenhanced solid portions of the lesion was performed. The signal intensity of the lesion was classified as hyperintense, isointense, or hypointense compared with the contralateral 
normal-appearing white matter on DWI map with $b=1000 \mathrm{~s} /$ $\mathrm{mm}^{2}$.

Another two experienced neuroradiologists (Z.X and J.L, with 8 and 3 years of brain MR imaging experience, respectively) independently and manually placed the region of interest (ROI) on ADC maps to encompass the contrast-enhancing solid portion of the tumors at the representative slice. For each tumor, the contrast-enhancing solid part was identified on contrast-enhanced T1-weighted images and matching ADC maps. The representative slice was defined as containing the largest area of the contrast-enhancing solid portion of each lesion and was selected independently by each observer. To obtain minimum $\mathrm{ADC}$ values $\left(\mathrm{ADC}_{\min }\right)$, a maximum of 6 ROIs depending on tumor size (range 2-6, size $20-30 \mathrm{~mm}^{2}$ ) were positioned without any overlapping inside the tumors on $\mathrm{ADC}$ maps. To obtain mean $\mathrm{ADC}$ values $\left(\mathrm{ADC}_{\text {mean }}\right)$, freehand ROI was delineated along the border of the contrastenhancing solid regions of each tumor. Cystic, necrotic, hemorrhagic, or apparent vessel regions that might interfere with ADC values were avoided.

The patients with supratentorial PA were further divided into two subgroups based on the tumor location: lobar PAs were located in the cerebral hemisphere, including the frontal lobe, temporal lobe, occipital lobe and parietal lobe, and other supratentorial PAs were located in the other supratentorial regions, including the suprasellar region, dorsal thalamus, and lateral ventricle.

\section{Data analysis}

All statistical analyses were performed with Statistical Package for the Social Sciences (SPSS 22.0 version for Windows, SPSS Inc., IBM) and MedCalc software (version 17.9.7 for Microsoft Windows 10; MedCalc Software, Mariakerke, Belgium). Results with $P$ values less than 0.05 were considered to indicate statistical significance. All parameters were presented as mean \pm standard deviation. The demographic data and conventional MRI features of supratentorial PA and PXA were compared by using the Chi-square test. Comparisons of the DWI signal intensity between patients with supratentorial PA and those with PXA were made with the nonparametric Mann-Whitney statistical test. The interobserver variability in determining the ADC parameters by two readers was evaluated by the intraclass correlation test (ICC). If the interobserver variability for ADC parameters has an excellent agreement (ICC > 0.75), the opinions of these two readers were intergraded through taking the average of values. The $\mathrm{ADC}_{\text {mean }}$ values and $\mathrm{ADC}_{\text {min }}$ values were compared using the unpaired Student's $t$ test in all supratentorial PA and PXA and then between lobar PA and PXA.

The receiver operating characteristic (ROC) analysis curves were constructed to determine the diagnostic accuracy and optimum threshold value of each ADC parameter for discriminating supratentorial PA, especially lobar PA, from PXA. The optimum threshold value defined was those that provided highest sensitivity and specificity jointly and maximized Youden index based on the decision plot. The sensitivity, specificity, positive predictive value, negative predictive value, accuracy, and area under the curve (AUC) based on optimum cut-off values for each ADC parameter were further calculated. Furthermore, comparisons of AUCs for different ADC parameters were made with a $Z$ test.

\section{Results}

Twenty-four pathologically proved cases, including 16 cases with supratentorial PA and 8 cases with PXA, were enrolled in this study. The demographic data and conventional MRI manifestations of supratentorial PA and PXA are summarized and compared in Table 1. There was no imbalance in the baseline clinical features, tumor locations, and conventional MR features between supratentorial PA and PXA.

The ADC parameters including $\mathrm{ADC}_{\text {mean }}$ values and $\mathrm{ADC}_{\text {min }}$ values calculated for supratentorial PA, lobar PA, and PXA are shown in Table 2. On DWI, the signal intensity in the contrast-enhancing regions of supratentorial PA was hyperintense $(n=4)$, isointense $(n=10)$, and hypointense $(n=2)$ relative to the contralateral normal-appearing white matter. Conversely, the signal intensity of PXA was hyperintense $(n=6)$, isointense $(n=2)$, and hypointense $(n=0)$. The signal intensity in the solid contrast-enhancing portions of PA was significantly higher than that of PXA $(P=0.02)$. Interobserver agreement of two readers for the semiquantitative analysis of all ADC parameters was excellent (ICC for $\mathrm{ADC}_{\text {mean }}, 0.97$; for $\left.\mathrm{ADC}_{\text {min }}, 0.78\right)$. Both $\mathrm{ADC}_{\text {mean }}$ values $\left(1542 \pm 186\right.$ vs $\left.1084 \pm 201 \times 10^{-6} \mathrm{~mm}^{2} / \mathrm{s} ; P<0.001\right)$ and $\mathrm{ADC}_{\text {min }}$ values $\left(1355 \pm 183\right.$ vs $988 \pm 180 \times 10^{-6} \mathrm{~mm}^{2} / \mathrm{s} ; P<$ $0.001)$ were significantly higher in supratentorial PA compared with PXA, respectively. In addition, Both $\mathrm{ADC}_{\text {mean }}$ values $\left(1517 \pm 218\right.$ vs $\left.1084 \pm 201 \times 10^{-6} \mathrm{~mm}^{2} / \mathrm{s} ; P<0.001\right)$ and $\mathrm{ADC}_{\text {min }}$ values $\left(1345 \pm 322\right.$ vs $988 \pm 180 \times 10^{-6} \mathrm{~mm}^{2} / \mathrm{s}$; $P<0.001)$ were also significantly higher in lobar PA compared with PXA, respectively. The results of the ROC curve analysis are given in Table 3. ROC curve analysis indicated that $\mathrm{ADC}_{\text {mean }}$ values seemed to account for the higher AUC (0.977) in differentiating supratentorial PA from PXA, with a cut-off value of $1189.8 \times 10^{-6} \mathrm{~mm}^{2} / \mathrm{s}$ and sensitivity and specificity of 93.8 and $100 \%$, respectively. But there were no significant differences in $\mathrm{AUC}$ between $\mathrm{ADC}_{\text {mean }}$ and $\mathrm{ADC}_{\text {min }}$ for differentiating supratentorial PA from PXA using $Z$ test $(Z=1.702, P=0.09)$. The $\mathrm{ADC}_{\text {mean }}$ values were also useful for discriminating lobar PA from PXA (AUC, 0.946) with a cut-off value of $1189.8 \times 10^{-6} \mathrm{~mm}^{2} / \mathrm{s}$ (sensitivity, $85.7 \%$; specificity, $100 \%$ ). The decision plot for ROC analysis is shown in Supplementary Figs. 1-4. Representative cases of 
Table 1 The demographic data and conventional MR imaging characteristics of supratentorial $\mathrm{PA}$ and PA

\begin{tabular}{|c|c|c|c|}
\hline & Supratentorial PA $(n=16)$ & PXA $(n=8)$ & $P$ value \\
\hline Gender (male/female) & $8 / 8$ & $6 / 2$ & 0.388 \\
\hline Age (years) & $19.2 \pm 8.8$ & & \\
\hline$(2-37)$ & $34.5 \pm 24.7$ & & \\
\hline$(13-72)$ & 0.264 & & \\
\hline Location & & & 0.234 \\
\hline Frontal lobe & 1 & 1 & \\
\hline Temporal lobe & 3 & 5 & \\
\hline Occipital lobe & 2 & 1 & \\
\hline Parietal lobe & 1 & 1 & \\
\hline Suprasellar region & 5 & & \\
\hline \multicolumn{4}{|l|}{ Dorsal thalamus } \\
\hline \multirow[t]{2}{*}{ Lateral ventricle } & 3 & & \\
\hline & 1 & & \\
\hline Radiological pattern & & & 1.000 \\
\hline Cystic-nodule & 7 & 4 & \\
\hline Predominantly solid & 9 & 4 & \\
\hline Peritumoral edema-no. (\%) & $9(56.25 \%)$ & $5(62.50 \%)$ & 1.000 \\
\hline Marked enhancement-no. (\%) & $10(62.5 \%)$ & $7(87.50 \%)$ & 1.000 \\
\hline "Dural tail” sign-no. $(\%)$ & $1(6.25 \%)$ & $2(22.22 \%)$ & 0.249 \\
\hline Inner table scalloping-no. (\%) & $4(25 \%)$ & $3(37.5)$ & 0.647 \\
\hline
\end{tabular}

$P A$ pilocytic astrocytoma, $P X A$ pleomorphic xanthoastrocytoma

Data in parentheses indicate the number of corresponding patients supratentorial PA and PXA mimicking each other are shown in Figs. 1 and 2.

\section{Discussion}

In this study, we used ADC values derived from DWI to discriminate supratentorial PA and PXA, which is frequently indistinguishable with conventional MRI. Our preliminary results suggested that both $\mathrm{ADC}_{\text {mean }}$ and $\mathrm{ADC}_{\text {min }}$ values based on contrast-enhancing portions of the tumor in supratentorial PA group were significantly higher than those in PXA group.

Both PA and PXA belong to low-grade astrocytoma and gross total resection without adjuvant treatment including radiotherapy or chemotherapy is considered as the preferred treatment. However, the surgical planning of supratentorial cystic PA may slightly differ from cystic PXA. The surgical procedures for removal of cystic components of PA and PXA include radical resection of cyst wall, biopsy of cyst wall, or no resection at all. Previous studies have reported that the cyst wall of PA was free from tumor tissues even if it was enhanced on MRI [19], and removal of cyst did not improve patients' survival in the series of 51 patients with cystic PA [20]. Furthermore, in clinical practice, radical removal of large cyst wall within supratentorial brain tumors may worsen motor deficit and increase the incidence of seizures [19]. Thus, a more conservative approach, leaving cyst walls intact, may be recommended for PA associated with large cysts. Nevertheless, Sakamoto et al. [21] showed that the cyst wall of PXA reflected neoplastic tissues, and tumors of PXA could recur from the cyst wall if tumor removal without resection of the cyst wall was implemented. In addition, PXA shows a strong intrinsic tendency to recur and undergo malignant transformation, especially if incomplete resection. Thus,
Table 2 Differences of histogram parameters in supratentorial PA, lobar PA, and PXA (mean \pm standard deviation)

\begin{tabular}{llllll}
\hline $\begin{array}{l}\text { Parameter } \\
\left(\times 10^{-6} \mathrm{~mm}^{2} / \mathrm{s}\right)\end{array}$ & Supratentorial PA $(n=16)$ & Lobar PA $(n=7)$ & PXA $(n=8)$ & ${ }^{\mathrm{a}} P$ & ${ }^{\mathrm{b}} P$ \\
\hline $\mathrm{ADC}_{\text {mean }}$ & $1542 \pm 186$ & $1517 \pm 218$ & $1084 \pm 201$ & $<0.001$ & $<0.001$ \\
$\mathrm{ADC}_{\text {min }}$ & $1355 \pm 183$ & $1345 \pm 322$ & $988 \pm 180$ & $<0.001$ & 0.001 \\
\hline
\end{tabular}

$P A$ pilocytic astrocytoma, $P X A$ pleomorphic xanthoastrocytoma

${ }^{\text {a }} P$ value of compared results of all supratentorial PA and PXA using unpaired Student's $t$ test. ${ }^{\mathrm{b}} P$ value of compared results of a subgroup of lobar PA and PXA 
Table 3 Diagnostic performance of ADC parameters for differentiating PA from PXA

\begin{tabular}{llllllll}
\hline parameter & $\mathrm{TV}\left(\times 10^{-6} \mathrm{~mm}^{2} / \mathrm{s}\right)$ & Sensitivity & Specificity & PPV & NPV & Accuracy & AUC \\
\hline${ }^{\mathrm{a}} \mathrm{ADC}_{\text {mean }}$ & 1189.8 & $93.8 \%$ & $100 \%$ & $100 \%$ & $88.9 \%$ & $95.8 \%$ & 0.977 \\
${ }^{\mathrm{a}} \mathrm{ADC}_{\text {min }}$ & 1063.5 & $75.0 \%$ & $87.5 \%$ & $92.3 \%$ & $63.6 \%$ & $79.2 \%$ & 0.820 \\
${ }^{\mathrm{b}} \mathrm{ADC}_{\text {mean }}$ & 1189.8 & $85.7 \%$ & $100 \%$ & $100 \%$ & $88.9 \%$ & $93.3 \%$ & 0.946 \\
${ }^{\mathrm{b}} \mathrm{ADC}_{\text {min }}$ & 1063.5 & $85.7 \%$ & $87.5 \%$ & $85.7 \%$ & $87.5 \%$ & $86.7 \%$ & 0.839 \\
\hline
\end{tabular}

$T V$ threshold value, $P P V$ indicates positive predictive value, $N P V$ negative predictive value, $A U C$ area under the curve

${ }^{\mathrm{a}}$ Comparison of all supratentorial PA and PXA. ${ }^{\mathrm{b}}$ Comparison of lobar PA and PXA radical tumor removal with resection of the cyst wall may be needed immediately for PXA to decrease postoperative recurrence incidence and long-term follow-up with repeated MRI is mandatory to detect tumor progression. A growing body of literature suggests that BRAF V600E mutation is a potentially targetable genetic abnormality in pediatric low-grade glioma, which is found frequently in PXA and less frequently in PA [22]. It has been demonstrated that PXA can be successfully treated with targeted BRAF mutations inhibitors in a small case series [23]. Therefore, the differentiation of PXA from PA may guide the targeted gene therapy in the future.

PA typically occurs in the cerebellum, whereas the overwhelming majority of PXA arises from the supratentorial brain. With the typical location and appearance of a welldelineated cerebellar cystic mass with mural nodule, the diagnosis of PA is easy. However, when located in the supratentorial region, PA shares its typical "a supratentorial cystic mass with enhancing mural nodule" appearance with PXA [6]. As presented in the previous studies, this typical MR imaging feature was found in $43.8 \%$ of the supratentorial PA and in $50.0 \%$ of PXA in our study [1,24-27]. In addition, the involvement of the adjacent leptomeninges (dural tail sign) has been reported to be a characteristic feature of PXA [26], which may be helpful in differentiating PXA from supratentorial PA. Lim et al. [28] reported the involvement of the adjacent leptomeninges in 12 of 22 patients with PXA. Whereas in the study by Crespo-Rodríguez et al. [26], only 3 of the 14 patients demonstrated enhancement of the adjacent leptomeninges. In this study, we also found that only 2 of the 7 PXAs demonstrated the "dural tail sign," consistent with the previous study by Crespo-Rodríguez et al. [26]. And our results showed that involvement of the adjacent
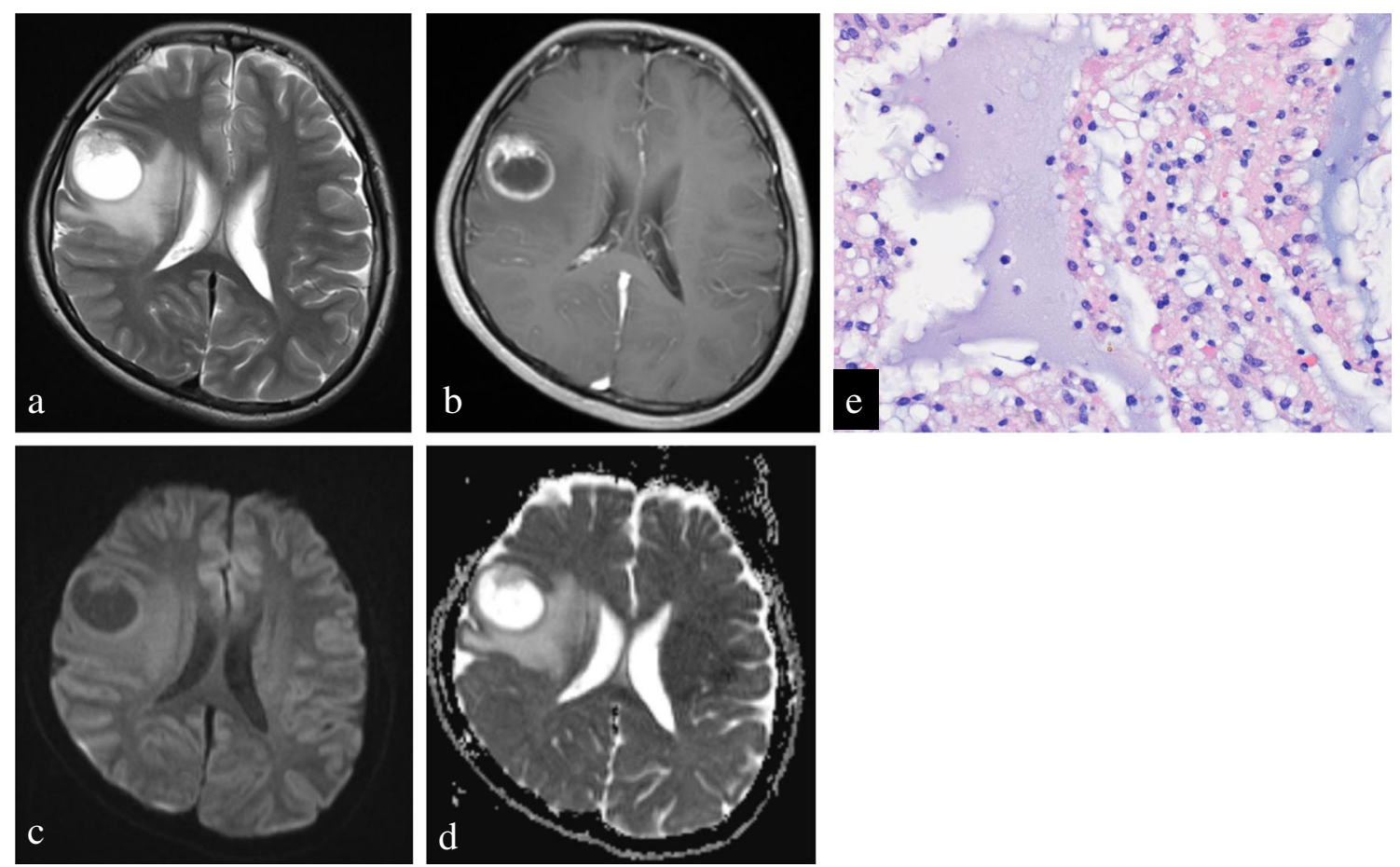

Fig. 1 Right frontal pilocytic astrocytoma in a 16-year-old woman. a Preoperative axial T2-weighted image shows a cystic mass with a mural nodule. b Contrast-enhanced axial T1WI shows intense enhancement of the mural nodule and cystic wall. c, $\mathbf{d}$ A corresponding axial diffusionweighted image and ADC map show that the contrast-enhancing solid

nodule of tumor shows a moderately increased diffusion compared with the normal-appearing white matter $\left(\mathrm{ADC}_{\text {mean }}=1621 \times 10^{-6} \mathrm{~mm}^{2} / \mathrm{s}\right)$. e The tumor shows a biphasic appearance in a loosely arranged myxoid background (original magnification, $\times 400$; hematoxylin-eosin stain) 

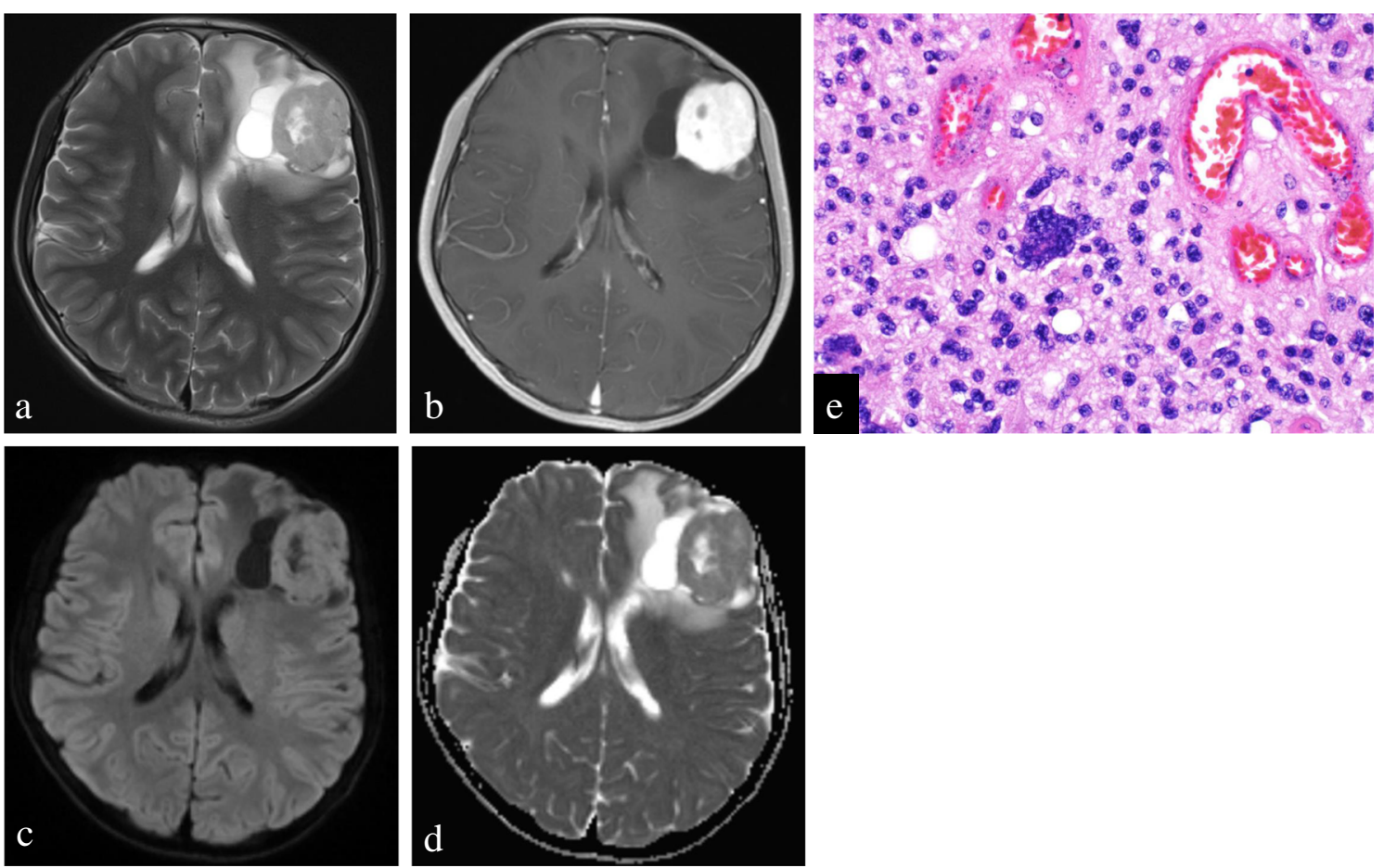

Fig. 2 Left frontal pleomorphic xanthoastrocytoma in a 13-year-old man. a Preoperative axial T2-weighted image shows a cystic mass with a large solid component. b Contrast-enhanced axial T1WI shows intense enhancement of the solid component. $\mathbf{c}, \mathbf{d}$ A corresponding axial diffusion-weighted image and ADC map show that the contrast-

enhancing solid component of tumor shows a slightly increased diffusion compared with the normal-appearing white matter $\left(\mathrm{ADC}_{\text {mean }}=1135 \times\right.$ $\left.10^{-6} \mathrm{~mm}^{2} / \mathrm{s}\right)$. e The tumor shows densely cellular glial elements, including a large multinucleated xanthomatous cell with foamy cytoplasm (original magnification, $\times 400$; hematoxylin-eosin stain)

leptomeninges was not a reliable MR feature for differentiating PXA from PA. Therefore, when a supratentorial cystic mass with solid-enhancing nodule is demonstrated on conventional MR images, there is less certainty as to whether the tumor is a supratentorial PA or a PXA.

DWI is a reliable and practicable MR technique and has been widely used to evaluate intracranial tumors $[11-13,15]$. There are only a few studies assessing DWI in PXA, all of which are anecdotal case reports or case series in the literature [29, 30]. Moore et al. [29] demonstrated in a case series that the mean ADC values were $912 \pm 219 \times 10^{-6} \mathrm{~mm}^{2} / \mathrm{s}$ in the 7 PXA tumors. In the present study, we found that the signal intensity in the contrast-enhancing areas of PXA tended to be hyperintense or isointense relative to normal white matter on DWI. Furthermore, the mean ADC values of PXA in this study were comparable to previous findings [29, 30]. Several studies that have evaluated ADC values in PA have compared them with high-grade glioma, medulloblastoma, and ependymomas [11, 31-33]. Previous studies of PA have demonstrated moderately high ADC values in PA $\left(1534-1688 \times 10^{-6} \mathrm{~mm}^{2} / \mathrm{s}\right)$ [11, 30, 31]. Our study showed that supratentorial PA demonstrated a moderately increased diffusion with $\mathrm{ADC}_{\text {mean }}$ of $1542 \pm 186 \times$ $10^{-6} \mathrm{~mm}^{2} / \mathrm{s}$, which was consistent with that in previous studies $[11,30,34]$. However, to the best of our knowledge, the usefulness of ADC values derived from DWI in differentiating supratentorial PA from PXA has not been investigated previously. In a study of brain tumors, Yamasaki et al. [30] reported that the ADC values were increased $(1659 \pm 260 \times$ $10^{-6} \mathrm{~mm}^{2} / \mathrm{s}$ ) in 3 patients with PA, while 1 PXA had relatively lower ADC value of $1009 \times 10^{-6} \mathrm{~mm}^{2} / \mathrm{s}$ (without statistical analysis). In this study, we found that all ADC values of supratentorial PA were significantly higher than those of PXA. Furthermore, we also performed a subgroup analysis of lobar PA and found that all ADC values of lobar PA were also significantly higher than those of PXA. This finding could be explained by different histopathological features of PA and PXA. Histologically, PA is a tumor of low-moderate cellularity within markedly loose myxoid background [35], whereas PXA is a hypercellular tumor composed of pleomorphic cells with mesenchymal-like morphology [36]. As previously reported [37], ADC values were inversely related to tumor cellular attenuation and tumor cell nucleus-to-cytoplasm ratio in terms of water molecules diffusivity within brain tumors. The association of higher ADC values of PA may reflect the lower cell density compared with PXA. In addition to the high cellularity, the tumor cells of PXA are characteristically large and multinucleate with a relatively high nucleus-to-cytoplasm ratio, which may restrict movement of water molecules [36, 38]. Taken together, we may postulate that the lower ADC values found in PXA strongly suggest an increased tumor cell density and a higher nucleus-to-cytoplasm ratio in PXA tumors compared with supratentorial PA. 
Recently, a histogram analysis based on whole-tumor has been used to indicate the heterogeneity of high-grade glioma and minimize ROI sampling errors [14, 39]. However, Xu et al. [39] suggested that the whole-tumor histogram method in assessing glioma did not yield higher interobserver agreement and better diagnostic performance than does the single-slice methods based on the minimum ADC value and took longer. In addition, the low-grade glioma including PA and PXA showed relatively less heterogeneity of tumor cellularity compared with high-grade glioma. Thus, we used single-slice measurements to indicate the diffusivity of water molecules in these two tumor types and shorter analysis time. Our results showed that both $\mathrm{ADC}_{\text {mean }}$ values and $\mathrm{ADC}_{\text {min }}$ values were significant for the contrast-enhancing portion of the tumor to discriminate supratentorial PA from PXA. Although ROC classification could only be used to illustrate the performance of a binary classifier system and AUC from ROC may be misleading if the ROC curves of two diagnostic tests intersect, ROC analysis is still a widely accepted method for evaluating the diagnostic accuracy of radiological tests [40]. In this study, we performed ROC analysis based on a binary comparison of PXA and PA, and ROC curve of ADC values does not intersect in our study. Our preliminary results showed that the accuracy levels were extremely high for $\mathrm{ADC}_{\text {mean }}$ values in distinguishing supratentorial PA from PXA (accuracy level, 95.8\%), as well as in distinguishing lobar PA form PXA (accuracy level, 93.3\%). Therefore, our findings suggest that DWI with ADC values may aid in the differential diagnosis of supratentorial PA and PXA, which is frequently challenging in clinical practice.

Besides the intrinsic limitations of the retrospective study, several other potential limitations of this study should be mentioned. Firstly, the number of the patients with PXA was rather small. Future investigations that include more patients are recommended to strengthen the statistical power. Secondly, because $\mathrm{ADC}$ values were not used to guide the biopsy in this retrospective study, it was not possible to evaluate the correlations between regions of lower ADC in PXA and hypercellularity point to point. These correlations should be performed in our future study. Thirdly, we could not excluded the presence of tiny hemorrhage within the tumor that may generate susceptibility blooming, hence influencing DWI evaluation, though there was no noticeable evidence of hemorrhage on conventional MRI. Fourthly, the diagnostic accuracy of DWI in our study refers only to the binary comparison of supratentorial PA and PXA, which may indicate these results cannot be used among PA, PXA, and other supratentorial young adult contrast-enhancing lesion, such as gangliocytoma, ganglioglioma, and high-grade glioma. However, the purpose of this study was to differentiate supratentorial PA from PA, which may be distinguishable on conventional MRI. And several conventional radiological features may be indicative of other supratentorial adult contrastenhancing lesion. For instance, the presence of intratumoral calcification was a consistent feature for gangliogliomas and gangliocytomas. And the infiltrative growth pattern, heterogeneous enhancement, and the presence of hemorrhage and necrosis should indicate high-grade gliomas. Finally, supratentorial PA and PXA are not amenable for a surgical excision despite of preoperative accurate differential diagnosis. However, the surgical strategies for cystic components of these two tumors may be different in order to reduce postoperative disability and mortality without increasing the recurrence rate. Further prospective studies are needed to confirm the value of differential diagnosis of these two tumors in guiding the surgical plans.

In conclusion, our results suggest that DWI is helpful in characterization and differentiation of supratentorial PA from PXA.

Acknowledgements The authors would like to acknowledge the contribution of Yu Zhang, M.D., in providing pathological analyses.

\section{Compliance with ethical standards}

Funding This study was funded by the Leading Project of the Department of Science and Technology of Fujian Province (No. 2016Y0042).

Conflict of interest The authors declare that they have no conflict of interest.

Ethical approval All procedures performed in the studies involving human participants were in accordance with the ethical standards of the institutional and/or national research committee and with the 1964 Helsinki Declaration and its later amendments or comparable ethical standards. For this type of study formal consent is not required.

Informed consent For this type of retrospective study formal consent is not required.

Open Access This article is distributed under the terms of the Creative Commons Attribution 4.0 International License (http:// creativecommons.org/licenses/by/4.0/), which permits unrestricted use, distribution, and reproduction in any medium, provided you give appropriate credit to the original author(s) and the source, provide a link to the Creative Commons license, and indicate if changes were made.

\section{References}

1. Koeller KK, Rushing EJ (2004) From the archives of the AFIP: pilocytic astrocytoma: radiologic-pathologic correlation. Radiographics 24(6):1693-1708. https://doi.org/10.1148/rg. 246045146

2. Ostrom QT, Gittleman H, Fulop J, Liu M, Blanda R, Kromer C, Wolinsky Y, Kruchko C, Barnholtz-Sloan JS (2015) CBTRUS statistical report: primary brain and central nervous system tumors diagnosed in the United States in 2008-2012. Neuro-Oncology 17(Suppl 4):iv1-iv62. https://doi.org/10.1093/neuonc/nov189

3. Louis DN, Perry A, Reifenberger G, von Deimling A, FigarellaBranger D, Cavenee WK, Ohgaki H, Wiestler OD, Kleihues P, Ellison DW (2016) The 2016 World Health Organization classification of tumors of the central nervous system: a summary. Acta 
Neuropathol 131(6):803-820. https://doi.org/10.1007/s00401-0161545-1

4. Perkins SM, Mitra N, Fei W, Shinohara ET (2012) Patterns of care and outcomes of patients with pleomorphic xanthoastrocytoma: a SEER analysis. J Neuro-Oncol 110(1):99-104. https://doi.org/10. 1007/s11060-012-0939-8

5. Ida CM, Rodriguez FJ, Burger PC, Caron AA, Jenkins SM, Spears GM, Aranguren DL, Lachance DH, Giannini C (2015) Pleomorphic xanthoastrocytoma: natural history and long-term follow-up. Brain Pathol 25(5):575-586. https://doi.org/10.1111/bpa. 12217

6. Gaudino S, Martucci M, Russo R, Visconti E, Gangemi E, D'Argento F, Verdolotti T, Lauriola L, Colosimo C (2017) MR imaging of brain pilocytic astrocytoma: beyond the stereotype of benign astrocytoma. Childs Nerv Syst 33(1):35-54. https://doi.org/ 10.1007/s00381-016-3262-4

7. Dodgshun AJ, Maixner WJ, Hansford JR, Sullivan MJ (2016) Low rates of recurrence and slow progression of pediatric pilocytic astrocytoma after gross-total resection: justification for reducing surveillance imaging. J Neurosurg Pediatr 17(5):569-572. https://doi. org/10.3171/2015.9.PEDS15449

8. Gnekow AK, Falkenstein F, von Hornstein S, Zwiener I, Berkefeld S, Bison B, Warmuth-Metz M, Driever PH, Soerensen N, Kortmann RD, Pietsch T, Faldum A (2012) Long-term follow-up of the multicenter, multidisciplinary treatment study HIT-LGG1996 for low-grade glioma in children and adolescents of the German Speaking Society of Pediatric Oncology and Hematology. Neuro-Oncology 14(10):1265-1284. https://doi.org/ 10.1093/neuonc/nos202

9. Wisoff JH, Sanford RA, Heier LA, Sposto R, Burger PC, Yates AJ, Holmes EJ, Kun LE (2011) Primary neurosurgery for pediatric lowgrade gliomas: a prospective multi-institutional study from the Children's Oncology Group. Neurosurgery 68(6):1548-1554; discussion 1554-1545. https://doi.org/10.1227/NEU.0b013e318214a66e

10. Coelho J, Nunes S, Salgado D (2015) Spontaneous malignant transformation of a pilocytic astrocytoma of cerebellum: case report. Child Neurol Open 2(1):2329048X14566813. https://doi.org/10. $1177 / 2329048 X 14566813$

11. de Fatima Vasco Aragao M, Law M, Batista de Almeida D, Fatterpekar G, Delman B, Bader AS, Pelaez M, Fowkes M, Vieira de Mello R, Moraes Valenca M (2014) Comparison of perfusion, diffusion, and MR spectroscopy between low-grade enhancing pilocytic astrocytomas and high-grade astrocytomas. AJNR Am J Neuroradiol 35(8):1495-1502. https://doi.org/10. 3174/ajnr.A3905

12. Xiao HF, Chen ZY, Lou X, Wang YL, Gui QP, Wang Y, Shi KN, Zhou ZY, Zheng DD, Wang DJ, Ma L (2015) Astrocytic tumour grading: a comparative study of three-dimensional pseudocontinuous arterial spin labelling, dynamic susceptibility contrast-enhanced perfusion-weighted imaging, and diffusion-weighted imaging. Eur Radiol 25(12):3423-3430. https://doi.org/10.1007/s00330-0153768-2

13. Zeng Q, Dong F, Shi F, Ling C, Jiang B, Zhang J (2017) Apparent diffusion coefficient maps obtained from high $b$ value diffusionweighted imaging in the preoperative evaluation of gliomas at $3 \mathrm{~T}$ : comparison with standard b value diffusion-weighted imaging. Eur Radiol 27:5309-5315. https://doi.org/10.1007/s00330-017-4910-0

14. Lu SS, Kim SJ, Kim N, Kim HS, Choi CG, Lim YM (2015) Histogram analysis of apparent diffusion coefficient maps for differentiating primary CNS lymphomas from tumefactive demyelinating lesions. AJR Am J Roentgenol 204(4):827-834. https://doi. org/10.2214/AJR.14.12677

15. Kang Y, Choi SH, Kim YJ, Kim KG, Sohn CH, Kim JH, Yun TJ, Chang KH (2011) Gliomas: histogram analysis of apparent diffusion coefficient maps with standard- or high-b-value diffusion- weighted MR imaging-correlation with tumor grade. Radiology 261(3):882-890. https://doi.org/10.1148/radiol.11110686

16. Gaudino S, Russo R, Verdolotti T, Caulo M, Colosimo C (2016) Advanced MR imaging in hemispheric low-grade gliomas before surgery; the indications and limits in the pediatric age. Childs Nerv Syst 32(10):1813-1822. https://doi.org/10.1007/s00381-016-3142-y

17. Tozer DJ, Jager HR, Danchaivijitr N, Benton CE, Tofts PS, Rees JH, Waldman AD (2007) Apparent diffusion coefficient histograms may predict low-grade glioma subtype. NMR Biomed 20(1):49-57. https://doi.org/10.1002/nbm.1091

18. Louis DNOH, Wiestler OD, Cavenee WK (2016) World Health Organization histological classification of tumours of the central nervous system. International Agency for Research on Cancer, Lyon

19. Beni-Adani L, Gomori M, Spektor S, Constantini S (2000) Cyst wall enhancement in pilocytic astrocytoma: neoplastic or reactive phenomena. Pediatr Neurosurg 32(5):234-239. https://doi.org/10. $1159 / 000028944$

20. Palma L, Guidetti B (1985) Cystic pilocytic astrocytomas of the cerebral hemispheres. Surgical experience with 51 cases and longterm results. J Neurosurg 62(6):811-815. https://doi.org/10.3171/ jns.1985.62.6.0811

21. Sakamoto T, Sakakibara Y, Hayashi T, Yamashita K, Sekino H, Ozawa T, Tadokoro M (1995) Recurrence of pleomorphic xanthoastrocytoma six years after total removal of mural nodule: a case report. No Shinkei Geka 23(10):941-945

22. Ho CY, Mobley BC, Gordish-Dressman H, VandenBussche CJ, Mason GE, Bornhorst M, Esbenshade AJ, Tehrani M, Orr BA, LaFrance DR, Devaney JM, Meltzer BW, Hofherr SE, Burger PC, Packer RJ, Rodriguez FJ (2015) A clinicopathologic study of diencephalic pediatric low-grade gliomas with BRAF V600 mutation. Acta Neuropathol 130(4):575-585. https://doi.org/10.1007/ s00401-015-1467-3

23. Chamberlain MC (2013) Salvage therapy with BRAF inhibitors for recurrent pleomorphic xanthoastrocytoma: a retrospective case series. J Neuro-Oncol 114(2):237-240. https://doi.org/10.1007/ s11060-013-1176-5

24. Goncalves VT, Reis F, Queiroz Lde S, Franca Jr M (2013) Pleomorphic xanthoastrocytoma: magnetic resonance imaging findings in a series of cases with histopathological confirmation. Arq Neuropsiquiatr 71(1):35-39

25. Yu S, He L, Zhuang X, Luo B (2011) Pleomorphic xanthoastrocytoma: MR imaging findings in 19 patients. Acta Radiol 52(2):223-228. https://doi.org/10.1258/ar.2010.100221

26. Crespo-Rodriguez AM, Smirniotopoulos JG, Rushing EJ (2007) MR and CT imaging of 24 pleomorphic xanthoastrocytomas (PXA) and a review of the literature. Neuroradiology 49(4):307315. https://doi.org/10.1007/s00234-006-0191-z

27. Borja MJ, Plaza MJ, Altman N, Saigal G (2013) Conventional and advanced MRI features of pediatric intracranial tumors: supratentorial tumors. AJR Am J Roentgenol 200(5):W483W503. https://doi.org/10.2214/AJR.12.9724

28. Lim S, Kim JH, Kim SA, Park ES, Ra YS, Kim CJ (2013) Prognostic factors and therapeutic outcomes in 22 patients with pleomorphic xanthoastrocytoma. J Korean Neurosurg Soc 53(5): 281-287. https://doi.org/10.3340/jkns.2013.53.5.281

29. Moore W, Mathis D, Gargan L, Bowers DC, Klesse LJ, Margraf L, Koral K (2014) Pleomorphic xanthoastrocytoma of childhood: MR imaging and diffusion MR imaging features. AJNR Am J Neuroradiol 35(11):2192-2196. https://doi.org/10.3174/ajnr.A4011

30. Yamasaki F, Kurisu K, Satoh K, Arita K, Sugiyama K, Ohtaki M, Takaba J, Tominaga A, Hanaya R, Yoshioka H, Hama S, Ito Y, Kajiwara Y, Yahara K, Saito T, Thohar MA (2005) Apparent diffusion coefficient of human brain tumors at MR imaging. Radiology 235(3):985-991. https://doi.org/10.1148/radiol.2353031338 
31. Schneider JF, Confort-Gouny S, Viola A, Le Fur Y, Viout P, Bennathan M, Chapon F, Figarella-Branger D, Cozzone P, Girard N (2007) Multiparametric differentiation of posterior fossa tumors in children using diffusion-weighted imaging and short echo-time 1H-MR spectroscopy. J Magn Reson Imaging : JMRI 26(6):13901398. https://doi.org/10.1002/jmri.21185

32. Li MD, Forkert ND, Kundu P, Ambler C, Lober RM, Burns TC, Barnes PD, Gibbs IC, Grant GA, Fisher PG, Cheshier SH, Campen CJ, Monje M, Yeom KW (2017) Brain perfusion and diffusion abnormalities in children treated for posterior fossa brain tumors. J Pediatr 185:173-180 e173. https://doi.org/10.1016/j.jpeds.2017.01.019

33. Poretti A, Meoded A, Huisman TA (2012) Neuroimaging of pediatric posterior fossa tumors including review of the literature. $\mathrm{J}$ Magn Reson Imaging : JMRI 35(1):32-47. https://doi.org/10. 1002/jmri.22722

34. Murakami R, Hirai T, Kitajima M, Fukuoka H, Toya R, Nakamura H, Kuratsu J, Yamashita Y (2008) Magnetic resonance imaging of pilocytic astrocytomas: usefulness of the minimum apparent diffusion coefficient (ADC) value for differentiation from high-grade gliomas. Acta Radiol 49(4):462-467. https://doi.org/10.1080/ 02841850801918555

35. Collins VP, Jones DT, Giannini C (2015) Pilocytic astrocytoma: pathology, molecular mechanisms and markers. Acta Neuropathol 129(6):775-788. https://doi.org/10.1007/s00401-015-1410-7
36. Kahramancetin N, Tihan T (2013) Aggressive behavior and anaplasia in pleomorphic xanthoastrocytoma: a plea for a revision of the current WHO classification. CNS Oncology 2(6):523-530. https:// doi.org/10.2217/cns. 13.56

37. Barajas RF Jr, Hodgson JG, Chang JS, Vandenberg SR, Yeh RF, Parsa AT, McDermott MW, Berger MS, Dillon WP, Cha S (2010) Glioblastoma multiforme regional genetic and cellular expression patterns: influence on anatomic and physiologic MR imaging. Radiology 254(2):564-576. https://doi.org/10.1148/radiol. 09090663

38. Jimenez-Heffernan JA, Freih Fraih A, Alvarez F, Barcena C, Corbacho C (2017) Cytologic features of pleomorphic xanthoastrocytoma, WHO grade II. A comparative study with glioblastoma. Diagn Cytopathol 45(4):339-344. https://doi.org/10.1002/dc.23660

39. Han X, Suo S, Sun Y, Zu J, Qu J, Zhou Y, Chen Z, Xu J (2017) Apparent diffusion coefficient measurement in glioma: influence of region-of-interest determination methods on apparent diffusion coefficient values, interobserver variability, time efficiency, and diagnostic ability. J Magn Reson Imaging : JMRI 45(3):722-730. https://doi.org/10.1002/jmri.25405

40. Halligan S, Altman DG, Mallett S (2015) Disadvantages of using the area under the receiver operating characteristic curve to assess imaging tests: a discussion and proposal for an alternative approach. Eur Radiol 25(4):932-939. https://doi.org/10.1007/s00330-0143487-0 